\title{
Temporary abdominal closure with zipper-mesh device for management of intra-abdominal sepsis
}

\section{Fechamento abdominal temporário com dispositivo tela-zíper para tratamento da sepse intra-abdominal}

Edivaldo Massazo Utiyama ${ }^{1}$; Adriano Ribeiro Meyer Pflug²; Sérgio Henrique Bastos Damous²; Adilson Costa Rodrigues-Jr2; Edna Frasson de Souza Montero'; Claudio Augusto Vianna Birolini²

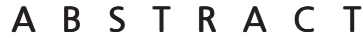

\begin{abstract}
Objective: to present our experience with scheduled reoperations in 15 patients with intra-abdominal sepsis. Methods: we have applied a more effective technique consisting of temporary abdominal closure with a nylon mesh sheet containing a zipper. We performed reoperations in the operating room under general anesthesia at an average interval of 84 hours. The revision consisted of debridement of necrotic material and vigorous lavage of the involved peritoneal area. The mean age of patients was 38.7 years (range, 15 to 72 years); 11 patients were male, and four were female. Results: forty percent of infections were due to necrotizing pancreatitis. Sixty percent were due to perforation of the intestinal viscus secondary to inflammation, vascular occlusion or trauma. We performed a total of 48 reoperations, an average of 3.2 surgeries per patient. The mesh-zipper device was left in place for an average of 13 days. An intestinal ostomy was present adjacent to the zipper in four patients and did not present a problem for patient management. Mortality was $26.6 \%$. No fistulas resulted from this technique. When intra-abdominal disease was under control, the mesh-zipper device was removed, and the fascia was closed in all patients. In three patients, the wound was closed primarily, and in 12 it was allowed to close by secondary intent. Two patients developed hernia; one was incisional and one was in the drain incision. Conclusion: the planned reoperation for manual lavage and debridement of the abdomen through a nylon mesh-zipper combination was rapid, simple, and well-tolerated. It permitted effective management of severe septic peritonitis, easy wound care and primary closure of the abdominal wall.
\end{abstract}

Key words: Abdominal Abscess. Abdominal Wall/surgery. Peritonitis. Sepsis/complications

\section{INTRODUCTION}

$\mathrm{D}$ espite significant technological progress in surgery, the treatment of intra-abdominal sepsis (IAS) remains challenging. IAS can be classified into complicated and uncomplicated cases. Complicated IAS occurs when infection spreads from the primary affected viscus to the peritoneal cavity and triggers a systemic inflammatory response, which is associated with a mortality of up to 30-35\% ${ }^{1}$. An early and efficient source of control combined with effective antibiotic therapy and modern intensive care and sepsis treatment is definitive for the outcome and prog-nosis of secondary peritonitis ${ }^{1,2}$. Surgery may have disappointing results when sepsis becomes clinically manifest through signs of multiple organ failure. Severe abdominal sepsis carries unacceptable mortality in surgical patients due to persisting intra-abdominal sepsis, recurrent sepsis, wound necrosis and dehiscence ${ }^{2}$. Several surgical strategies have been developed to reduce mortality caused by intra-abdominal sepsis. A prospective randomized controlled study of radical peritoneal debridement and standard surgical management did not confirm the value of the peritoneal radical debridement ${ }^{3}$. Postoperative peritoneal lavage requires close surveillance of the fluid and electrolyte balance, and there is also a tendency for fistulas to develop at the drain sites ${ }^{4}$. Leaving the abdominal incision completely open allows for complete drainage of the purulent exudation from the peritoneal cavity and has markedly reduced mortality ${ }^{5}$. Leaving the abdomen open without creating a temporary closure does not reduce intraperitoneal abscess, and nursing care becomes difficult in the postoperative period, as there may be loss of fluids, electrolytes, and heat and the development of enteric fistulas; for these reasons, this method has been abandoned $^{6}$. Performing scheduled laparotomies every three to four days until the peritoneal cavity is clean is an attractive treatment approach, though this method suffers the disadvantages of frequent evisceration, requirement for respirators, and severe patient discomfort ${ }^{5,7-10}$.

1. Surgery Department, Medical School, Universidade de São Paulo. São Paulo State, Brazil; 2. General and Trauma Surgery, Hospital das Clínicas, Medical School, Universidade de São Paulo, São Paulo State, Brazil. 
However, there are two current indications for having an open abdomen in cases of complicated IAS. The first corresponds to cases with no possibility of closing the abdomen due to edema of the abdominal viscera, and the second occurs when the complete eradication of the infectious focus is not possible ${ }^{11-14}$. There are several techniques that can be used to assist in temporary abdominal closure when scheduled reoperation is chosen for the treatment of cases of complicated IAS. Surgical treatment based on a zipper-mesh combination that provides access to the abdominal cavity can be used as an alternative method to improve mortality rates in patients with severe intra-abdominal sepsis ${ }^{15,16}$.

This study describes the experience in 15 patients and also provides a literature review regarding the in-hospital mortality and morbidity of temporary abdominal closure with the zipper-mesh device.

\section{METHODS}

The authors reviewed the records of 15 patients who underwent planned relaparotomy for complicated IAS between 1985 and 1990 and included only those who used the zipper-mesh device for temporary closure of the abdomen. Six cases of IAS were caused by pancreatitis, three were caused by large bowel perforation, three were caused by postoperative anastomotic leakage and there was one case each caused by appendicitis, rectal perforation, and mesenteric thrombosis. All cases were treated at the Hospital das Clínicas, Universidade de São Paulo.

All patients who underwent scheduled relaparotomy for complicated IAS and also had a zippermesh device for abdominal access were included in the study. However, patients who died after the placement of the zipper-mesh device and prior to relaparotomy were excluded.

At the time of surgery, the presenting problem was addressed using standard surgical techniques. Six patients underwent debridement of necrotic tissues; for the repair of intestinal perforations, three patients underwent repair by excision with anastomosis and four underwent repair with ostomy; and two patients had a distal pancreatectomy with splenectomy.

The authors used a 25-centimeter $(\mathrm{cm})$ nylon zipper with jagged ribbons that can be separated completely. The mesh was built with nylon line measuring 0.2286 millimeters $(\mathrm{mm})$ in diameter with a pore size of $0.6180 \mathrm{~mm}$. A ribbon zipper without a cursor was tailored to four centimeters from the edge of the rectangular patch of mesh, which was sized $30 \times 8 \mathrm{~cm}$. The other tape was stitched with the cursor at the edge of a rectangular screen that was sized $30 \times 5 \mathrm{~cm}$ (Figure 1). Thus, one side of the mesh passed over the jagged edges to protect the intestinal loops during movement of the cursor to the zipper (Figure 2).
The mesh was trimmed to fit the wound circumferentially and may have been secured to the abdominal wall fascia with a running nylon suture. Sterile gauze was placed over the mesh, and the patient was transferred to the surgical intensive care unit. Planned relaparotomies were performed every 48-120 hours (mean time 84 hours) for repeated lavage and debridement. Early on, a concerted effort was made to lyse all adhesions that formed between episodes of lavage and to debride any tissue that had become necrotic. At the end of the lavage, the mesh was re-zipped, and sterile gauze was replaced over the mesh. Planned relaparotomies were discontinued when the abdomen was judged to be clean and when the infection had subsided. All surgical manipulations were performed in the operating room

On the day of the first surgery, the APACHE ॥ score was calculated for each patient ${ }^{17}$. All patients were treated with broad-spectrum antibiotics, and microbiologic specimens were taken for aerobic and anaerobic cultures.

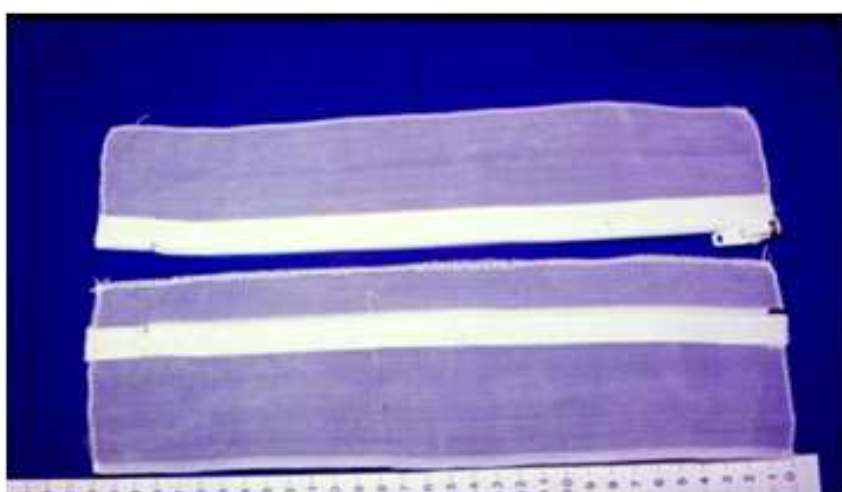

Figure 1 - Device constructed with nylon mesh-zipper. Note that the device consists of two separate, independent segments.

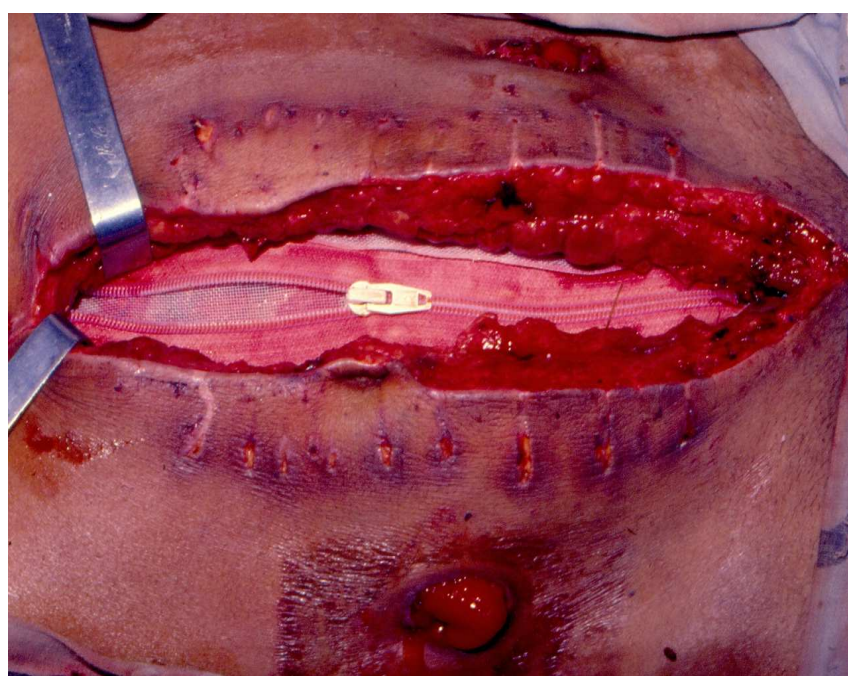

Figure 2 - $\quad$ One side of the mesh passes over the jagged edges to protect the intestinal loops during movement of the cursor to the zipper. 
A review of the literature was performed to identify all reports of temporary abdominal closure techniques with a mesh-zipper device between January 1936 and December 2010 that mentioned the indication for the open abdomen, the closure rate, and the mortality and morbidity. The Medline database was searched using the following keywords: open abdomen; laparostomy; mesh; zipper; temporary abdominal closure; fascial. Only studies published in English were included in this review. Reports of temporary abdominal wall closure that used a zipper sewn directly into the fascia were excluded.

\section{RESULTS}

The patients consisted of 11 men and four women, with a mean age of 35 years (range 15-72). The patients remained in the hospital for an average of 29.9 days (nine to 61 days). The APACHE II score ranged from three to 24 and had a mean of 13.3 (Table 1). The pathogens detected from the infection of the abdominal cavity were gram-positive and gram-negative bacteria, as well as anaerobes. The number of bacterial species isolated for each patient ranged from one to eight. The most common bacteria isolated were $S$. aureus (46.6\% of patients), $E$. coli (46.6\% of patients) and $P$. mirabilis, $P$. aeruginosa, $S$. faecalis (33.3\% of patients).

The number of relaparotomies ranged from two to seven (mean 3.2). The mean use duration of the zippermesh device was 13 days (ranged from six to 27 days). One patient experienced displacement of the mesh and required re-exploration. Another patient suffered from acute myocardial infarct and died before the mesh could be removed. One patient had the mesh replaced four times to reduce the retraction of the fascial edges. Finally, one patient who had undergone cholecystectomy developed a biliary fistula. The fistula was naturally exteriorized through the skin wound and closed spontaneously. The abdominal wall was closed primarily with running absorbable stitches. The skin was closed in three patients.

Four patients (2.6\%) died within 30 days of the first surgery. The first patient had upper intestinal bleeding 23 days after the resolution of the intra-abdominal infection. The second had an acute myocardial infection. The third had pneumonia, and the fourth had endocarditis.

At the end of treatment, all patients underwent closure of the abdominal wall (Figure 3). None of the patients developed intestinal fistulas or abscesses following treatment, and none died directly from treatment. Two patients developed incisional hernia, and they successfully underwent surgery. Four patients had surgery to close the ostomies. One patient died two days after the intestinal closure due to intra-abdominal hemorrhage.

After the literature review, 12 articles were selected ${ }^{16,18-28}$ (Table 2).

\section{DISCUSSION}

Persistent or recurrent intra-abdominal sepsis continues to have high mortality rates in patients with complicated IAS ${ }^{13,15}$. The most frequent cause of death in these patients is the persistence of septic foci or incomplete drainage of these foci, which leads to the development or worsening of established multiple organ failures ${ }^{13-15}$.

Table 1 - Patient data.

\begin{tabular}{|c|c|c|c|c|c|c|c|}
\hline Case & $\begin{array}{c}\text { Age/ } \\
\text { Gender }\end{array}$ & Indication & APACHE-II & $\begin{array}{l}\text { Number of } \\
\text { abdominal } \\
\text { operations }\end{array}$ & $\begin{array}{c}\text { Days of } \\
\text { mesh-zipper } \\
\text { use }\end{array}$ & $\begin{array}{l}\text { Length of } \\
\text { hospital } \\
\text { stay (days) }\end{array}$ & Outcome \\
\hline 1 & $28 / F$ & Fecal peritonitis & 14 & 3 & 14 & 24 & Alive \\
\hline 2 & $15 / F$ & Fecal peritonitis & 14 & 3 & 11 & 27 & Alive \\
\hline 3 & $36 / \mathrm{M}$ & Fecal peritonitis & 24 & 3 & 12 & 32 & Died \\
\hline 4 & $23 / \mathrm{M}$ & Necrotizing pancreatitis & 20 & 4 & 12 & 44 & Alive \\
\hline 5 & $72 / \mathrm{M}$ & Fecal peritonitis & 16 & 2 & 8 & 9 & Died \\
\hline 6 & $75 / F$ & Fecal peritonitis & 12 & 3 & 8 & 21 & Alive \\
\hline 7 & 49 / M & Necrotizing pancreatitis & 15 & 3 & 8 & 9 & Died \\
\hline 8 & $28 / \mathrm{M}$ & Necrotizing pancreatitis & 6 & 2 & 6 & 25 & Alive \\
\hline 9 & $40 / M$ & Fecal peritonitis & 7 & 5 & 26 & 44 & Alive \\
\hline 10 & $28 / \mathrm{M}$ & Necrotizing pancreatitis & 7 & 3 & 12 & 30 & Alive \\
\hline 11 & $20 / \mathrm{M}$ & Fecal peritonitis & 20 & 4 & 26 & 61 & Alive \\
\hline 12 & $50 / \mathrm{M}$ & Fecal peritonitis & 3 & 2 & 7 & 17 & Alive \\
\hline 13 & $33 / F$ & Necrotizing pancreatitis & 11 & 7 & 27 & 55 & Alive \\
\hline 14 & $26 / \mathrm{M}$ & Fecal peritonitis & 10 & 2 & 7 & 20 & Alive \\
\hline 15 & $58 / M$ & Necrotizing pancreatitis & 21 & 2 & 11 & 27 & Died \\
\hline
\end{tabular}


The principles of prevention and treatment of persistent or recurrent intra-abdominal sepsis include debridement of dead tissue, drainage of septic foci and prevention of reaccumulation ${ }^{9,15,16}$. Initial radical debridement has not been reproduced with good results ${ }^{3}$, and multiple operations are frequently required.

Considering that diffuse secondary peritonitis constitutes a major abscess that can be treated by broad drainage, an open abdomen technique has been suggested by some authors. However, the open abdomen is not recommended due to high rates of complications and difficulty in the management of patients. The temporary closure of the abdomen facilitates patient care, allows access to the abdominal cavity for relaparotomy and ultimately allows for permanent closure of the abdomen ${ }^{5,9-11}$.

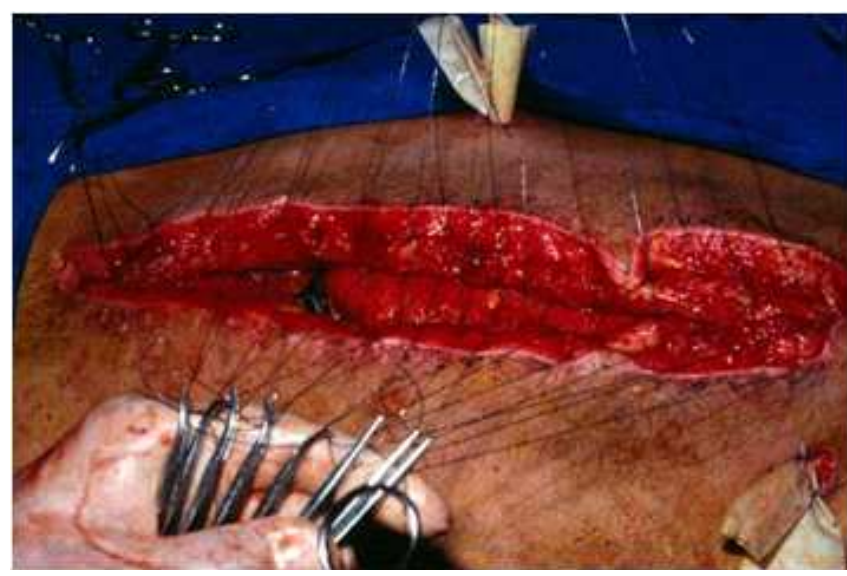

Figure 3 - Primary closure of the abdominal wall.
While the use of an open mesh abdomen technique alone decreases the problems associated with evisceration and ventilation, it is insufficient to prevent the reaccumulation of septic foci in the intestinal loop areas and deeper recesses of the abdomen. This issue can be resolved by the adoption of daily manual exploration and lavage of the abdominal cavity through a zipper inserted in a marlex mesh abdominal closure ${ }^{16}$.

In 1936, the first reference to a zipper in the abdominal wall was described in the treatment of inoperable carcinoma of the stomach by direct electrical coagulation. The physician performed a gastrostomy by suturing the gastric wall to the skin to facilitate access to the gastric injury. Due to leakage of gastric juice and to prevent dermatitis and facilitate access to the tumor, the stomach was occluded by a zipper sewed onto the skin ${ }^{29}$.

The use of a zipper in the abdominal wall was forgotten until 1982, when Leguit described a fast and secure method for abdominal reoperation using a conventional nylon zipper in two patients with intestinal vascular disease. A conventional $10-\mathrm{cm}$ zipper was stitched onto the surface of a marlex mesh with a running suture and sterilized with ethylene oxide. A small longitudinal slit was made in the marlex mesh, just outside the midline of the zipper, to allow entry to the abdomen in a trapdoor-like fashion and to avoid damage to the bowel by the zipper ${ }^{18}$. The zipper could be sutured to the edges of the transverse incision, as done by Stone in 1985, for drainage of pancreatic abscesses. Access to the abdominal cavity is easy via the zipper and can prevent evisceration ${ }^{30}$. For more sufficient prevention of $\mathrm{IAH}$, a zipper has been combined with mesh for temporary abdominal closure in cases of complicated IAS

Table 2 - Complications observed.

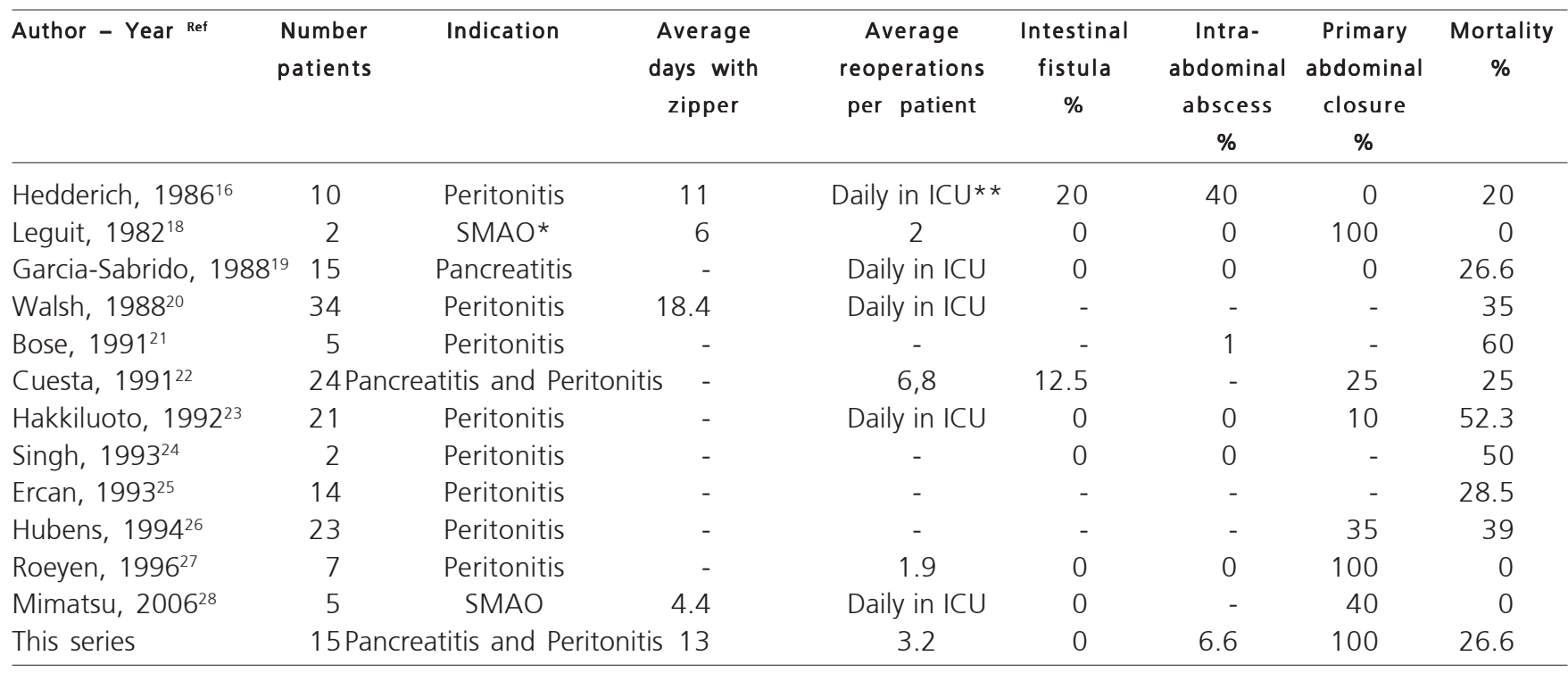

Ref $=$ reference

*SMAO = superior mesenteric arterial occlusion

$* * I C U=$ intensive care unit 
due to intestinal perforation or anastomosis dehiscence; this approach was proposed by Hedderich et al. ${ }^{16}$ in the USA and by Teichmann et al., in Germany ${ }^{31}$. Although this device allows easy access to the abdominal cavity, mandatory exploration prior to wound closure or healing appears disadvantageous ${ }^{32}$.

The indications for zip closure treatment remain debatable. The mortality varies between $7 \%$ and $67 \%$, which likely results from varying methods of patient selection ${ }^{10,16,20,31}$. Van Goor et al. ${ }^{10}$ defined the indication for zip closure as diffuse suppurative peritonitis caused by colonic perforation or anastomotic dehiscence in which the abdominal cavity remains grossly contaminated after the initial laparotomy. Garcia-Sabrido et al. ${ }^{19}$ recommend zipper laparotomy when there is uncertain control or incomplete drainage of septic foci, when a compromised anastomosis must be observed, or when bowel viability is uncertain in cases of mesenteric ischemia. According to Walsh et al. ${ }^{20}$, it is likely that the approach was used too early in some patients and too late in others. The author limited the use of the open abdomen technique to a defined subgroup of patients with diffuse, non-localizing peritonitis. These patients usually had one re-exploration or necrotizing pancreatitis accompanied by infection, and patients with discrete abscesses or regional peritonitis were excluded ${ }^{20}$. We advocate this criterion in our study.

In a series of 10 cases, Hedderich et al. ${ }^{16}$ reported a survival rate of $80 \%$. Among patients undergoing the zipper technique, none developed fistulas. The daily explorations were well tolerated by patients with only mild doses of anesthetics. Despite daily laparotomy, paralytic ileus was not a problem. However, all patients developed abdominal wall hernias. Another series ${ }^{8}$ of eight patients reported no deaths. All patients had the abdomen closed without a fascia defect, and none developed an incisional hernia. According to the author, stomas pose no special problems, and the design of the fastener is such that loops of bowel cannot become trapped in its closure mechanism. The mortality rate of $26.6 \%$ observed in this series was similar to that expected in patients with APACHE II scores of 13. A Spanish study ${ }^{19}$ of 15 patients with severe intraabdominal sepsis and APACHE II scores of greater than 15, among whom the mean APACHE II score was 25 , reported a mortality rate of $26.5 \%$ as opposed to the $45 \%$ mortality expected by Knaus et al. ${ }^{17}$. A Dutch study ${ }^{9}$ of 24 consecutive patients reported effective control of intra-abdominal infection, as a residual abscess was found in only one patient. Moreover, cultures from the abdominal cavities of 21 patients grew less than $10^{3} \mathrm{cfu} / \mathrm{ml}$ in $62 \%, 76 \%$, and $95 \%$ of patients after two, three, and four relaparotomies, respectively. In this series, no patient developed intraperitoneal abscess or intestinal fistula during reoperation or after permanent closure of the abdominal wall. However, bowel perforation and fistulas were common complications, and we encountered these particularly after more than four relaparotomies, which suggests that multiple planned relaparotomies have risks.

All papers on temporary abdominal closure techniques with a mesh-zipper device that mentioned the indication for the open abdomen, the closure rate, and the mortality and morbidity were reviewed (Table 2 ). The search identified 29 articles describing the mesh-zipper device. After reading the abstracts, the authors excluded 17 articles because they did not meet the inclusion criteria. There were no randomized controlled trials or other comparative studies. The 12 included articles described case series with 162 patients ${ }^{16,18-28}$. In this series, the mesh-zipper device stayed in place for 13 days. The average number of surgeries per patient was 3.2. No patients developed intestinal fistula, but $6.6 \%$ of patients developed intra-abdominal abscess. Definitive closure of the abdomen was possible in $100 \%$ of patients, and mortality was $26.6 \%$. Among papers from the literature review, the mesh-zipper device remained in place for an average of ten days (range 4.4 to 18.4), and patients underwent an average of seven reoperations (ranging from 1.9 to 18). The incidence of intestinal fistula was $16 \%$, and $20 \%$ developed intra-abdominal abscess. Primary wound closure occurred in an average of $52 \%$ of patients (ranging from 0 to $100 \%$ ), and the average mortality was $28 \%$ (ranging from 0 to $60 \%$ ). These results differed from our series with regards to the incidence of intra-abdominal abscess, intestinal fistula and definitive closure of the abdominal wall. The low incidence of intraabdominal abscess is likely because the reoperations were performed in the operating room, which allowed for rapid control of an infectious focus that is not possible at the bedside. The reoperations were performed at shorter intervals, and the gradual approximation of the incision edges explains the absence of intestinal fistula and the achievement of permanent closure in 100\% of our patients.

Temporary abdominal closure with the meshzipper device allowed easy access to the abdominal cavity, and the planned reoperation was effective in cleaning the peritoneal surface and prevented the formation of residual abscesses. There were no deaths due to intra-abdominal sepsis in our series. All patients had primary closure of the abdominal wall. There were no intestinal fistulas. Planned relaparotomies using the zip mesh closure are not always harmless. The patients must be properly selected, and the closure device must be used at the correct time. These two issues remain unclear in the literature.

The zipper-mesh device is a good alternative for temporary abdominal closure in patients with severe intraabdominal sepsis. 


\title{
R E S U M O
}

\begin{abstract}
Objetivo: apresentar nossa experiência com reoperações agendadas em 15 pacientes com sepse intra-abdominal. Métodos: foi empregada uma técnica mais eficaz que consiste em fechamento abdominal temporário com uma folha de malha de nylon contendo um zíper. Realizamos as reoperações no centro cirúrgico, sob anestesia geral, com um intervalo médio de 84 horas. A revisão consistiu de desbridamento de material necrosado e lavagem vigorosa da área peritoneal envolvida. A média de idade dos pacientes foi 38,7 anos; 11 pacientes eram do sexo masculino e quatro do sexo feminino. Resultados: Quarenta por cento das infecções foram devido à pancreatite necrosante. Sessenta por cento foram ocasionadas por perfuração intestinal secundária à inflamação, oclusão vascular ou trauma. Foram realizadas 48 reoperações, média de 3,2 operações por paciente. 0 dispositivo tela-zíper foi deixado no local por uma média de 13 dias. Um estoma intestinal estava presente ao lado do zíper em quatro pacientes e não ocasionou complicação para o paciente. A mortalidade foi 26,6\%. Nenhuma fístula resultou dessa técnica. Quando a doença intra-abdominal estava sob controle, o dispositivo de fecho do tipo de rede foi removido, e a fáscia foi fechada em todos os pacientes. Em três pacientes, a ferida foi fechada primariamente, em 12 permitiu-se fechar por intenção secundária. Dois pacientes desenvolveram hérnia: uma incisional e outra na incisão de drenagem. Conclusão: A nova operação prevista para lavagem manual e desbridamento do abdômen através de uma combinação de tela-zíper em nylon foi rápida, simples e bem tolerada, permitindo uma gestão eficaz da peritonite séptica grave, fácil tratamento das feridas e fechamento primário da parede abdominal
\end{abstract}

Descritores: Abscesso Intra-Abdominal. Parede Abdominal/cirurgia. Peritonite. Sepse/complicações.

\section{REFERENCES}

1. Loganathan A, Gunn J. The surgical treatment of intra-abdominal sepsis. Surgery. 2012;30(12):662-6.

2. Strobel O, Werner J, Büchler MW. Surgical therapy of peritonitis Chirurg. 2011;82(3):242-8

3. Polk HC Jr, Fry DE. Radical peritoneal debridement for established peritonitis. The results of a prospective randomized clinical trial. Ann Surg. 1980;192 (3):350-5.

4. Stephen M, Loewenthal J. Continuing peritoneal lavages in highrisk peritonitis. Surgery. 1979;85(6):603-6.

5. Steinberg D. On leaving the peritoneal cavity open in acute generalized suppurative peritonitis. Am J Surg. 1979;137(2):21620.

6. Schein M, Saadia R, Decker GG. The open management of the septic abdomen. Surg Gynecol Obstet. 1986;163(6):587-92.

7. Charleux H, Mongredien P, Anfroy JP, Normand P, Fichelle A. Nonclosure of the abdominal wall in the surgery of peritonitis. Chirurgie. 1980;106(1):63-5.

8. Hannon RJ, Hood JM, Curry RC. Temporary abdominal closure: a new product. Br J Surg. 1992;79(8):820-1.

9. Wittmann DH, Aprahamian C, Bergstein JM. Etappenlavage: advanced diffuse peritonitis managed by planned multiple laparotomies utilizing zippers, slide fastener, and Velcro analogue for temporary abdominal closure. World J Surg. 1990;14(2):21826.

10. van Goor H, Hulsebos RG, Bleichrodt RP. Complications of plannedre laparotomy in patients with severe general peritonitis.Eur J Surg. 1997;163(1):61-6.

11. Open Abdomen Advisory Panel, Campbell A, Chang M, Fabian T, Franz $M$, Kaplan $M$, et al. Management of the open abdomen: from initial operation to definitive closure. Am Surg. 2009;75(11 Suppl):S1-22.

12. Leppäniemi AK. Laparostomy: why and when? Crit Care 2010:14(2):216.

13. Robledo FA, Luque-de-León $E$, Suárez $R$, Sánches $P$, de-la-Fuente $M$, Vargas $A$, et al. Open versus closed management of the abdomen in the surgical treatment of severe secondary peritonitis: a randomized clinical trial. Surg Infect. 2007;8(1):63-72.

14. Waibel $\mathrm{BH}$, Rotondo MF. Damage control for intra-abdominal sepsis. Surg Clin North Am. 2012;92(2):243-57, viii.

15. Ordoñez CA, PuyanaJC. Management of peritonitis in the critically ill patient. Surg Clin North Am. 2006;86(6):1323-49.
16. Hedderich GS, Wexler MJ, McLean AP, Meakins JL. The septic abdomen: open management with Marlex mesh with a zipper Surgery. 1986;99(4):399-408

17. Knaus WA, Draper EA, Wagner DP, Zimmerman JE. APACHE II: a severity of disease classification system. Crit Care Med. 1985;13(10):818-29.

18. Leguit P Jr. Zip-closure of the abdomen. NethJ Surg. 1982;34(1):401 .

19. Garcia-Sabrido JL, Tallado JM, Christou NV, Polo JR, Valdecantos E. Treatment of severe intra-abdominal sepsis and/or necrotic foc by an 'open-abdomen' approach. Zipper and zipper-mesh techniques. Arch Surg. 1988;123(2):152-6.

20. Walsh GL, Chiasson P, Hedderich G, Wexler MJ, Meakins JL. The open abdomen. The Marlex mesh and zipper technique: a method of managing intraperitoneal infection. Surg Clin North Am. 1988;68(1):25-40.

21. Bose SM, Kalra M, Sandhu NP. Open management of septic abdomen by Marlex mesh zipper. Aust N Z J Surg. 1991;61(5):385-8.

22. Cuesta MA, Doblas M, Castañeda L, Bengoechea E. Sequential abdominal reexploration with the zipper technique. World J Surg. 1991;15(1):74-80.

23. Hakkiluoto A, Hannukainen J. Open management with mesh and zipper of patients with intra-abdominal abscesses or diffuse peritonitis. Eur J Surg. 1992;158(8):403-5.

24. Singh K, Chhina RS. Role of zipper in the management of abdominal sepsis. Indian J Gastroenterol. 1993;12(1):1-4

25. Ercan F, Korkmaz A, Aras N. The zipper-mesh method for treating delayed generalized peritonitis. Surg Today. 1993;23(3):205-14.

26. Hubens G, Lafaire C, De Praeter M, Ysebaert D, Vaneerdeweg W, Heytens L, et al. Staged peritoneal lavages with the aid of a Zipper system in the treatment of diffuse peritonitis. Acta Chir Belg. 1994;94(3):176-9.

27. Roeyen G, Hubens G, Vaneerdeweg W, Mahieu L, Eyskens E. Scheduled relaparotomies using a zipper system for the treatment of diffuse generalized peritonitis in children. Acta Chir Belg. 1996;96(5):201-5.

28. Mimatsu K, Oida T, Kanou H, Miyake H, Amano S. Open abdomen management after massive bowel resection for superior mesenteric arterial occlusion. Surg Today. 2006;36(3):2414

29. Strauss AA. A new method and end results in the treatment of carcinoma of the stomach and rectum by surgical diathermy (electrical coagulation). JAMA. 1936;106(4):285-6. 
30. Stone HH. Strom PR, Mullins RJ. Pancreatic abscess management by subtotal resection and packing. World J Surg. 1984;8(3):340-5.

31. Teichmann W, Wittmann DH, Andreone PA. Scheduled reoperations (etappen lavage) for diffuse peritonitis. Arch Surg. 1986;121(2):147-52.

32. Schachtrupp A, Fackeldey V, Klinge U, Hoer J, Tittel A, Toens C, et al. Temporary closure of the abdominal wall (laparostomy). Hernia. 2002;6(4):155-62.
Received 03/03/2014

Accepted for publication 10/05/2014

Conflict of interest: none

Source of funding: none

Address for correspondence:

Edivaldo M. Utiyama

E-mail: eutiyama@hotmail.com 